\title{
Ureteric stenting versus non-stenting following uncomplicated ureteroscopic lithotripsy: A Prospective randomized trial.
}

\section{Saddam Al Demour ( $\nabla$ saldemour@ju.edu.jo )}

The University of Jordan School of Medicine https://orcid.org/0000-0003-4044-0927

\section{Adel Alrabadi}

The University of Jordan School of Medicine

Abedallatif AlSharif

The University of Jordan School of Medicine

\section{Mera Ababneh}

Jordan University of Science and Technologyl School of Pharmacy

\section{Motaz Melhem}

The University of Jordan School of Medicine

\section{Hammam Mansi}

The University of Jordan School of Medicine

\section{Sa'id Aljamal}

The University of Jordan School of Medicine

\section{Mohammad Abufaraj}

The University of Jordan School of Medicine

\section{Research article}

Keywords: Ureteroscopy, lithotripsy, uncomplicated, Double j stent, ureteric stone

Posted Date: November 26th, 2019

DOI: https://doi.org/10.21203/rs.2.17484/v1

License: (c) (1) This work is licensed under a Creative Commons Attribution 4.0 International License. Read Full License 


\section{Abstract}

\section{Background:}

There is no consensus about whether a double-J ureteric stent (DJ-US) should be placed following uncomplicated ureteroscopy for stone retrieval. This study aimed to compare three groups of patients who underwent uncomplicated ureteroscopic lithotripsy (URSL) and to evaluate whether stents could be eliminated after the procedure.

\section{Methods:}

A total of 105 patients underwent uncomplicated URSL for ureteric stones were prospectively randomized into three groups: group 1 (34 patients) with DJ-US, group 2 (35 patients) with DJ-US on extraction string, and group 3 (36 patients) with no DJ-US after the procedure. The outcomes measured were; postoperative Visual Analog Score (VAS) for flank pain and dysuria score, urgency, frequency, suprapubic pain, hematuria, analgesia requirement, operative time, re-hospitalization, and return to normal physical activity.

\section{Results:}

Mean operative time was significantly longer in groups 1 and 2 compared to group 3 [mean time \pm SD, $22.2 \pm 9.1 \mathrm{~min}, 20.2 \pm 6 \mathrm{~min}, 15.1 \pm 7.1 \mathrm{~min}$ respectively, $p<0.0001]$. The results of the VAS for flank pain and dysuria scores, urgency, frequency, hematuria, and suprapubic pain showed a significant difference at all time points of follow-up, with significantly higher in groups 1 and 2 compared to group 3 . Further analysis showed that measured outcomes, and analgesia need for groups 1 and 2 were similar, at all time points except at week 1 and 1 month where group 2 patient's had less symptoms.

\section{Conclusion:}

DJ-US placement appear to be unnecessary in procedures considered uncomplicated by operating urologists during surgery. The advantages of DJ-US with extraction string over DJ-US only include earlier and easy removal with earlier relief of symptoms, and less analgesia requirements.

\section{Background}

Urolithiasis is a major clinical and economic burden for healthcare systems; it is a highly prevalent condition with a high rate of recurrence with a large impact on quality of life [1, 2].

The incidence and prevalence of stone disease are increasing, likely due to improvements in clinical diagnostic procedures and changes in nutritional and environmental factors [3-5]. 
In the last decade, surgical management of ureteric stones has changed dramatically due to improvements in instruments such as smaller caliber semi-rigid and flexible ureteroscopies and intracorporeal lithotripsy including holmium laser. These advances have made ureteroscopy as an outpatient procedure, less traumatic, safer and more efficacious modality for the treatment of stones in all locations of the ureter [6-8].

Double-J ureteric stent (DJ-US) insertion following ureteroscopic lithotripsy is common practice and widely accepted as best practice for patients who are pregnant or have solitary or transplanted kidneys, renal impairment, or pyonephrosis. DJ-US is also used for complicated ureteroscopies involving bleeding, ureteric trauma, or large residual stone burden requiring stenting $[9,10]$.

However, there is no consensus about whether a DJ-US should be placed following uncomplicated ureteroscopy for stone retrieval. Furthermore, the definition of uncomplicated ureteroscopic lithotripsy remains controversial [11]. Despite this controversy, the majority of urologists routinely insert DJ-US stents, justified by the hypothetical fact that stent placement promotes the passage of residual stone fragments and clots, lowers the risk of stricture formation, prevents ureteral obstruction and occurrence of renal colic resulting from ureteral edema following stone retrieval $[12,13]$.

Nevertheless, DJ-US insertion after ureteroscopy is associated with significant morbidity including pain, infection, and irritative voiding symptoms. DJ-US insertion may also cause serious complications such as upward migration, sepsis, breakage of a forgotten stent, encrustation, knotting of the proximal end, and stone formation, thereby adding to patient morbidity and increasing costs [14-16]. The frequency and severity of these complications may be reduced by use of DJ-US with an extraction string attached. This would also spare the patient from undergoing a second procedure to remove the stent, thus enabling earlier removal and decreasing morbidity [17]. However, randomized prospective trials have found that routine stenting after uncomplicated ureteroscopy is not necessary because stenting might be associated with higher postoperative morbidity $[18,19]$.

Comparative studies between these 3 approaches (DJ-US, DJ-US with extraction string, and no DJ-US insertion) are lacking; most of the available literature compares stenting and not stenting. We found no studies that compared all 3 approaches. In addition, among these studies, there is no consensus on the definition of uncomplicated ureteroscopic lithotripsy. Indeed, available literature evaluating the benefits of ureteric stents often include not only uncomplicated ureteroscopy but also complicated ones. This results in inhomogeneous groups of patients and does not allow one to make solid conclusions about study results.

Here, in this randomized prospective trial, we included simple visual criteria for defining uncomplicated ureteroscopic lithotripsy. A homogenous group of patients undergoing uncomplicated ureteroscopies for stone removal were randomized into 3 different groups: DJ-US, DJ-US with extraction string, and no DJUS. 


\section{Methods}

\section{Study design and approval:}

This was a randomized controlled trial conducted between February 2016 and January 2019 at Jordan University Hospital in Amman, Jordan. The study protocol was approved by the Institutional Review Board. All participants were informed about the study design and signed written informed consent forms in accordance with the Declaration of Helsinki. The patients meeting the inclusion criteria were randomly allocated into three groups using a balanced blocked random number list.

\section{Patient recruitment:}

A total of 123 patients with unilateral ureteric stones were managed by ureteroscopy. The patients were then prospectively randomized into 3 equal groups using randomization table. Group 1 consisted of patients in whom a DJ-US was inserted after stone removal, Group 2 included patients in whom a DJ-US with extraction string was inserted, and Group 3 included those in whom no DJ-US was inserted after stone removal.

\section{Inclusion and exclusion criteria:}

Patients 18 years of age or older with unilateral ureteric stones managed by ureteroscopy were included in the study. Exclusion criteria included stone size $<2 \mathrm{~cm}$, bilateral ureteral stones, incomplete stone removal due to impacted stones, failed ureteroscopic access to the stone, stone migration to the kidney. Patients were also excluded if they were pregnant or had an active urinary tract infection, solitary kidney, ureteral stent placed preoperatively, severe mucosal injury or perforation, or suspected additional ureteral pathology such as ureteral stricture, urothelial carcinoma, or polyp.

\section{Patient assessment:}

All patients were admitted to the hospital and assessed preoperatively by history and physical examination. Laboratory data collected included complete blood counts (CBCs), kidney function tests (KFTs), urinalyses, and urine cultures. Stone size and location were assessed preoperatively by plain X-ray of the kidney, ureter, and bladder (KUB) and by non-enhanced computed tomography (NECT). Upper ureteric stones were defined as those located above the superior border of the sacroiliac joint. Mid ureteric stones were defined as those located between the superior and inferior borders of the sacroiliac joint, and distal ureteric stone as those located below the inferior border of the sacroiliac joint.

\section{Technique:}


All procedures were performed under general anesthesia by the same experienced surgeon (SA) after a discussion with the patients. Intravenous antibiotics were given to all patients at the time of anesthesia induction and maintained throughout the hospital stay. Patients were then switched to oral antibiotics for another 3 days.

We started the procedure by cystoscopy, inserting a safety guide wire ( 0.038 inch) into the ureter under fluoroscopic guidance. A semirigid ureteroscope (Wolf 8.9 Fr) was passed into the ureter beside the guide wire without ureteral dilation. Stones were extracted under vision using a Dormia stone basket (1.9 Fr, $90 \mathrm{~cm}$ length) and, if required, intracorporeal pneumatic lithoclast (EMS LithoClast) was used to fragment the stones into small pieces. At the end of the ureteroscopy, the ureter was inspected to rule out presence of residual stones or ureteric injury.

Ureteroscopic lithotripsy was defined as uncomplicated if the stone was fragmented and extracted without ureteric injury, which included ureteric perforation or severe mucosal injury. This was assessed visually by the operating urologist (SA) during ureteroscopy. If obvious mucosal injury or ureteral perforation was present, the procedure was considered complicated. Therefore, a DJ-US was inserted, and the case was excluded from the study.

For those patients randomized to Group 1, a DJ-US (4.8 Fr, $28 \mathrm{~cm}$ length) was inserted via cystoscopy under fluoroscopic guidance. For patients in Group 2, a DJ-US (4.8 Fr, $28 \mathrm{~cm}$ length) was inserted as above, but with an extraction string fixed to the external genitalia. For patients in Group 3, the ureter was left without a DJ-US.

Operative times were calculated starting at the insertion of the cystoscope until final removal of all endoscopes. For patients in Group 1, the DJ-US was left for 2 weeks, then the patients were readmitted to the day surgery unit for DJ-US removal under general anesthesia. For patients in Group 2, the DJ-US with extraction string was left for 48 hours, then removed on the inpatient floor before patient discharge.

\section{Outcome measures and follow-up:}

All patients were evaluated 5 hours after the procedure and on the first and second postoperative days on the inpatient floor. Patients were also evaluated at 1 week, 4 weeks, and 3 months after surgery in the outpatient clinic at Jordan University Hospital. The outcomes of interest were flank pain, dysuria, urgency, frequency, suprapubic pain, hematuria, need of analgesia, and readmission to the hospital.

Preoperative and postoperative flank pain and dysuria scores were assessed using a 10-cm (NECT) from 0 to 10, in which 0 to 3 represented mild pain, 4 to 6 represented moderate pain, and 7 to 10 represented severe pain. Flank pain score, dysuria score, frequency, urgency, suprapubic pain, hematuria, and need for analgesia were measured during the hospital stay and after discharge. Postoperative imaging, including KUB and renal ultrasound (US), was performed at 1 week and at 3 months in the clinic. 


\section{Statistical Analysis:}

Continuous variables were presented as mean \pm standard deviation (SD) while categorical variables were presented as numbers and percent. For continuous variables, Kruskal Wallis $\mathrm{H}$ test was used to compare variables among the three arms of the study and Mann-Whitney $U$ test was used to compare variables within each pair of arm. Chi-square test was used to compare categorical variables. All tests were twosided, and statistical significance was set at $p$-value $\leq 0.05$. The analysis was carried out using SPSS version 22. Sample size was predetermined by assuming a $5 \%$ type I statistical error and a $10 \%$ type II statistical error, and applying standard statistical table.

\section{Results}

A total of 123 patients were eligible to participate in the study. After ureteroscopy, we excluded 18 patients due to mucosal injury, impacted stones, failure of access, or stone migration. After exclusion, Group 1 included 34 patients, Group 2 included 35 patients, and Group 3 included 36 patients (Figure 1).

Patients in the 3 study groups were comparable in their characteristics and method of stone retrieval (Table 1). Mean operative time was statistically different among the groups $(P=<0.0001)$ (Table 1). All patients were discharged 2 days after the procedure. Two patients from Group 3 required rehospitalization 3 days after discharge due to severe flank pain with elevated serum creatinine; they were managed conservatively with antibiotics and analgesia. The stone-free rate was $100 \%$ at 3 months for all groups. We did not observe hydronephrosis in any patients during follow-up.

The results of the VAS for flank pain and dysuria showed a significant difference at all time points of follow-up, with a higher mean VAS in Groups 1 and 2 compared to that in Group 3. Further analysis showed that scores for Groups 1 and 2 were similar, except that Group 2 experienced less pain and dysuria at 1 week and at 1 month compared to Group 1 (Table 2).

Lower urinary tract symptoms, namely, urgency, frequency, hematuria, and suprapubic pain, were less frequent in Group 3 compared to Groups 1 and 2. Furthermore, these symptoms were significantly less frequent for Group 2 at 1 week and at 1 month compared to Group 1 (Table 3). Regarding analgesia, we found statistically significant differences in the need for analgesia at all-time points of follow-up, with Groups 1 and 2 requiring more analgesia (Table 3 ).

Within 7 days of the procedure, 26 patients (91.7\%) of Group 1, 33 patients (94.3\%) of group 2, and 35 patients (97.2\%) of Group 3 returned to normal physical activity, and, within 1 month, all 105 patients returned to normal physical activity.

\section{Discussion}

Ureteral stent placement after ureteroscopic lithotripsy is common clinical practice. It is traditionally encouraged to prevent complications, such as ureteral stricture, flank pain and renal failure due to ureteric 
edema or passage of stone fragments and clots [20]. On the other hand, the insertion of a ureteral stent after ureteroscopic lithotripsy may result in symptoms such as flank pain, urgency, dysuria, hematuria or other rare complications such as stent migration or urosepsis. In addition, routine ureteral stent placement may be associated with prolonged operating time and costs [21-24].

Ureteroscopy and intracorporeal lithotripsy are becoming less invasive, resulting in decreased morbidity. Postoperative stenting has become the most frequent cause of morbidity in ureteroscopic stone removal. Joshi et al. and Ucuzal et al $[25,26]$, reported that patients with stents had undesirable consequences and a significantly negative impact on patients' quality of life. Therefore, whether it is necessary to routinely insert a stent following ureteroscopy for ureteric calculi remains controversial.

This ongoing controversy has prompted the use of stents with extraction strings to prevent early complications of stone removal, particularly ureteral obstruction. This would also allow noninvasive stent removal and reduction in stent dwell time, ultimately leading to decreased morbidity, physical burden, and overall procedure costs $[27,28]$.

Comparative studies between stent, no stent, and stent with extraction string in patients who underwent uncomplicated ureteroscopic lithotripsy are lacking. The definition of uncomplicated ureteroscopic lithotripsy used in our study is simple and based principally on visual assessment by an operating urologist. The results of this study cannot be generalized to patients undergoing complicated ureteroscopic lithotripsy, as they were excluded.

In our prospective, randomized controlled study, flank pain scores were lowest for patients in Group 3 at all time points. Flank pain scores for patients in Group 2 dropped to levels comparable to those in Group 3 by the end of the first week. These scores were significantly lower than those in Group 1. In our study, pain score results in stented and non-stented groups were in agreement with some previous studies, although some studies reported contradicting results $[29,30]$.

These discrepant results may be due to the use of different methods for pain assessment; few studies used categorical assessments of pain (mild, moderate, or severe), while others used a more detailed scale (10-cm VAS). In addition, time intervals for pain assessment varied among these studies.

Similarly, dysuria scores were the lowest for patients in Group 3 at all-time points. Dysuria for patients in Groups 1 and 2 were comparable in the first 48 hours. However, by the end of first week, dysuria scores for patients in Group 2 dropped significantly in comparison to those in Group 1. At 1 month, patients in Groups 2 and 3 had comparable dysuria scores and still reported significantly less dysuria than patients in Group 1.

As expected, patients in Group 3 reported less urgency, frequency, suprapubic pain, and hematuria compared to those in Groups 1 and 2 at all-time points. The presence of these symptoms dropped significantly for patients in Group 2 after the stent with extraction string was removed. These lower urinary tract symptoms were likely related to the presence of the stent and irritation induced by presence 
of a foreign body [19]. Reduction in lower urinary tract symptoms is the most significant advantage of the stent on string approach. These findings are concordant with a study by Djaladat $\mathrm{H}$ et al., who used shortterm ureteric stents attached to a Foley catheter, allowing early and easy stent removal [31].

Patients in Group 3 required less analgesia than patients in other groups at all-time points. It was also observed that there was a sharp decline in analgesia requirements for Group 2 patients after stent removal ( $82.9 \%$ of patients required analgesia at 24 hours, and only $22.9 \%$ at 7 days). Meanwhile, $76.5 \%$ of patients in Group 1 continued to require analgesia at 1 week.

The exact etiology of symptoms related to double-J stent insertion is unknown. It has been postulated that the intravesical portion of the stent results in increased pressure in the renal pelvis during micturition as well as increased bladder mucosa irritation [32, 33].

As shown in Figure $(X)$, the presence of these symptoms was observed more often in Group 2 patients for the first 48 hours. We believe that foreign body irritation (i.e., the extraction string) adds to lower urinary tract symptoms.

The success of ureteroscopic lithotripsy is usually measured by stone-free rate at follow-up. None of our patients was found to have any residual stone at 3 months, meaning that the success rate of ureteroscopic lithotripsy was identical in all 3 groups (100\%).

Another advantage of a non-stent approach is faster operation time (average of 15.1 minutes). Double-J stents with an extraction string had a similar operation time as double-J stents only (average of 20.2 minutes versus 22.2 minutes, respectively). However, patients with a stent with extraction string did not require a second admission for stent removal; consequently, they experienced faster total operation times, less anesthesia, and lower costs.

The only disadvantage found for the no stent approach was the readmission rate; 2 of our patients was hospitalized 3 days after the procedure for management of pain and an increased serum creatinine level. None of the patients who had a stent with string had any spontaneous stent dislodgment or urgent readmission.

The current study has some limitations, including the absence of validated assessment of cost, quality of life and symptom score for proper assessment of flank pain and lower urinary tract symptoms. Another limitation is the absence of a precise assessment of the amount of analgesia used.

\section{Conclusion}

No stent approach resulted in the smoothest postoperative course, and stent placement is not necessary in procedures determined to be uncomplicated by operating urologists at the time of surgery. The advantages of DJ-US with extraction string over DJ-US only include earlier relief of flank pain and dysuria, rapid relief of urgency, frequency, suprapubic pain, and hematuria, and less analgesia requirements. 
Furthermore, patients who had a stent with extraction string did not require a second procedure for stent removal, and none had spontaneous stent dislodgment.

\section{Abbreviations}

URSL: Ureteroscopic lithotripsy

DJ-US: Double-J ureteric stent

CBCs: Complete blood counts

KFTs: Kidney function tests

KUB: Kidney, ureter, and bladder

NECT: Non-enhanced computed tomography

VAS: Visual Analog Score

\section{Declarations}

Ethical approval and consent to participate: Registration number and date of approval in Institution review board committee at Jordan University Hospital: No. (2/2016), date: 2/2/2016. Written informed consent was obtained from all individual participants included in the study.

Consent to publish: Not applicable.

Availability of data and material: Not applicable.

Competing interests: The authors declare that they have no Competing of interest.

Funding: Not applicable.

Authors' contributions: Al Authors read and approved the manuscript.

SA: Protocol/project development, Data collection or management, Manuscript writing/editing.

AR: Data collection or management, Manuscript writing/editing.

AS: Data collection or management, Manuscript writing/editing.

MA: Data analysis, Manuscript writing/editing.

MM: Data collection or management.

HM: Data collection or management. 
SJ: Data collection or management, Data analysis.

MA: Manuscript writing/editing.

Acknowledgements: Not applicable

\section{References}

1. Semins MJ, Matlaga BR. Medical evaluation and management of urolithiasis. Therapeutic advances in urology. 2010 Feb;2(1):3-9.

2. Scales Jr CD, Smith AC, Hanley JM, Saigal CS, Urologic Diseases in America Project. Prevalence of kidney stones in the United States. European urology. 2012 Jul 1;62(1):160-5.

3. Romero V, Akpinar H, Assimos DG. Kidney stones: a global picture of prevalence, incidence, and associated risk factors. Reviews in urology. 2010;12(2-3):e86.

4. Prezioso D, Illiano E, Piccinocchi G, Cricelli C, Piccinocchi R, Saita A, Micheli C, Trinchieri A. Urolithiasis in Italy: an epidemiological study. Archivio Italiano di Urologia e Andrologia. 2014 Jun 30;86(2):99-102.

5. Seklehner S, Laudano MA, Jamzadeh A, Del Pizzo JJ, Chughtai B, Lee RK. Trends and inequalities in the surgical management of ureteric calculi in the USA. BJU international. 2014 Mar;113(3):476-83.

6. Ibrahim HM, Al-Kandari AM, Shaaban HS, Elshebini YH, Shokeir AA. Role of ureteral stenting after uncomplicated ureteroscopy for distal ureteral stones: a randomized, controlled trial. The Journal of urology. 2008 Sep;180(3):961-5.

7. Francesca F, Scattoni V, Nava L, Paolo P, Rigatti P. Failures and complications of transurethral ureteroscopy in 297 cases: conventional rigid instruments vs. small caliber semirigid ureteroscopes. European urology. 1995;28:112-5.

8. Yaycioglu O, Guvel S, Kilinc F, Egilmez T, Ozkardes H. Results with 7.5 F versus 10F rigid ureteroscopes in treatment of ureteral calculi. Urology. 2004 Oct 1;64(4):643-6.

9. Knudsen BE, Beiko DT, Denstedt JD. Stenting after ureteroscopy: pros and cons. The Urologic clinics of North America. 2004 Feb;31(1):173-80.

10. Foreman D, Plagakis S, Fuller AT. Should we routinely stent after ureteropyeloscopy?. BJU international. 2014 Nov;114:6-8.

11. Auge BK, Sarvis JA, L'Esperance JO, Preminger GM. Practice patterns of ureteral stenting after routine ureteroscopic stone surgery: a survey of practicing urologists. Journal of endourology. 2007 Nov 1;21(11):1287-92.

12. Cevik I, Dillioglugil O, Akdas A, Siegel Y. Is stent placement necessary after uncomplicated ureteroscopy for removal of impacted ureteral stones?. Journal of endourology. 2010 Aug 1;24(8):1263-7.

13. Hosking DH, McCOLM SE, Smith WE. Is stenting following ureteroscopy for removal of distal ureteral calculi necessary?. The Journal of urology. 1999 Jan;161(1):48-50. 
14. Picozzi S, Carmignani L. A knotted ureteral stent: A case report and review of the literature. Urology annals. 2010 May;2(2):80.

15. Schulze KA, Wettlaufer JN, Oldani G. Encrustation and stone formation: complication of indwelling ureteral stents. Urology. 1985 Jun 1;25(6):616-9.

16. Rembrink K, Goepel M, Meyer-Schwickerath M. The forgotten double J stent. Urologia internationalis. 1992;49(2):119-20.

17. Joshi HB, Stainthorpe A, MacDonagh RP, Keeley FX, Timoney AG. Indwelling ureteral stents: evaluation of symptoms, quality of life and utility. The Journal of urology. 2003 Mar;169(3):1065-9.

18. Pengfei S, Yutao L, Jie Y, Wuran W, Yi D, Hao Z, Jia W. The results of ureteral stenting after ureteroscopic lithotripsy for ureteral calculi: a systematic review and meta-analysis. The Journal of urology. 2011 Nov 1;186(5):1904-9.

19. Song T, Liao B, Zheng S, Wei Q. Meta-analysis of postoperatively stenting or not in patients underwent ureteroscopic lithotripsy. Urological research. 2012 Feb 1;40(1):67-77.

20. Harmon WJ, Sershon PD, Blute ML, Patterson DE, Segura JW. Ureteroscopy: current practice and long-term complications. The Journal of urology. 1997 Jan;157(1):28-32.

21. Wang H, Man L, Li G, Huang G, Liu N, Wang J. Meta-analysis of stenting versus non-stenting for the treatment of ureteral stones. PloS one. 2017 Jan 9;12(1):e0167670.

22. Nabi G, Cook J, N'dow J, McClinton S. Outcomes of stenting after uncomplicated ureteroscopy: systematic review and meta-analysis. bmj. 2007 Mar 15;334(7593):572.

23. Joshi HB, Stainthorpe A, MacDonagh RP, Keeley FX, Timoney AG. Indwelling ureteral stents: evaluation of symptoms, quality of life and utility. The Journal of urology. 2003 Mar;169(3):1065-9.

24. Richter S, Ringel A, Shalev M, Nissenkorn I. The indwelling ureteric stent: a 'friendly'procedure with unfriendly high morbidity. BJU international. 2000 Mar;85(4):408-11.

25. Joshi HB, Okeke A, Newns N, Keeley Jr FX, Timoney AG. Characterization of urinary symptoms in patients with ureteral stents. Urology. 2002 Apr 1;59(4):511-6.

26. Ucuzal M, Serçe P. Ureteral Stents: Impact on Quality of Life. Holistic nursing practice. 2017 Mar 1;31(2):126-32.

27. Oliver R, Wells H, Traxer O, Knoll T, Aboumarzouk O, Biyani CS, Somani BK, YAU Group. Ureteric stents on extraction strings: a systematic review of literature. Urolithiasis. 2018 Apr 1;46(2):129-36.

28. Barnes KT, Bing MT, Tracy CR. Do ureteric stent extraction strings affect stent-related quality of life or complications after ureteroscopy for urolithiasis: a prospective randomised control trial. BJU international. 2014 Apr;113(4):605-9.

29. El Harrech Y, Abakka N, El Anzaoui J, Ghoundale O, Touiti D. Ureteral stenting after uncomplicated ureteroscopy for distal ureteral stones: a randomized, controlled trial. Minimally invasive surgery. 2014;2014.

30. Kenan I, Salih B, Suat E, Huseyin E, Vehbi K. Is routine ureteral stenting necessary after uncomplicated ureteroscopic lithotripsy for lower ureteral stones larger than $1 \mathrm{~cm}$ ?. Urological 
research. 2008 May 1;36(2):115-9.

31. Djaladat $H$, Tajik P, Payandemehr P, Alehashemi S. Ureteral catheterization in uncomplicated ureterolithotripsy: a randomized, controlled trial. European urology. 2007 Sep 1;52(3):836-41.

32. Thomas RA. Indwelling ureteral stents: impact of material and shape on patient comfort. Journal of endourology. 1993 Apr;7(2):137-40.

33. Maldonado-Avila M, Garduño-Arteaga L, Jungfermann-Guzman R, Manzanilla-Garcia HA, RosasNava E, Procuna-Hernandez N, Vela-Mollinedo A, Almazan-Treviño L, Guzman-Esquivel J. Efficacy of Tamsulosin, Oxybutynin, and their combination in the control of double-j stent-related lower urinary tract symptoms. International braz j urol. 2016 Jun;42(3):487-93.

\section{Tables}

Table 1: Patients demographic and clinical characteristics. 


\begin{tabular}{|c|c|c|c|c|}
\hline & $\begin{array}{l}\text { Group } 1 \\
\text { (DJ-US) } \\
\mathrm{N}=34 \\
\mathrm{n}(\%)\end{array}$ & \begin{tabular}{|l|} 
Group 2 \\
(DJ-US on str \\
$\mathrm{N}=35$ \\
$\mathrm{n}(\%)$
\end{tabular} & \begin{tabular}{|l|} 
Group 3 \\
rg $\phi$ DJ-US) \\
$N=36$ \\
$n(\%)$
\end{tabular} & P-Value \\
\hline $\begin{array}{l}\text { years } \\
\pm \pm S D \text { ) } \\
\end{array}$ & $46.2 \pm 12.7$ & $40.8 \pm 12.8$ & $43.8 \pm 10.3$ & 0.2042 \\
\hline re & $\begin{array}{c}7(20.6) \\
27(79.4)\end{array}$ & $\begin{array}{c}9(25.7) \\
26(74.3)\end{array}$ & $\begin{array}{c}7(19.4) \\
29(80.6)\end{array}$ & 0.7500 \\
\hline $\begin{array}{l}\text { tion } \\
\text { ary or secondary } \\
\text { ielor or graduate) }\end{array}$ & $\begin{array}{l}13(38.2) \\
21(61.8) \\
\end{array}$ & $\begin{array}{l}11(31.4) \\
24(68.6) \\
\end{array}$ & $\begin{array}{l}10(27.8) \\
26(72.2) \\
\end{array}$ & 0.6392 \\
\hline $\left.\mathrm{kg} / \mathrm{m}^{2}\right)($ Mean $\pm \mathrm{SD})$ & $27.8 \pm 3.5$ & $27.1 \pm 4.3$ & $28.8 \pm 4.1$ & 0.1802 \\
\hline $\begin{array}{l}\text { size in } \mathrm{mm} \\
( \pm S D)\end{array}$ & $7.5 \pm 2.4$ & $7 \pm 1.5$ & $6.7 \pm 1.6$ & 0.1967 \\
\hline $\begin{array}{l}\text { location } \\
2\end{array}$ & $\begin{array}{c}12(35.3) \\
19(55.9) \\
3(8.8)\end{array}$ & $\begin{array}{c}16(45.7) \\
14(40) \\
5(14.3)\end{array}$ & $\begin{array}{c}14(40) \\
17(48.6) \\
4(11.4)\end{array}$ & 0.7670 \\
\hline$\overline{\text { lity }}$ & $\begin{array}{l}16(47.1) \\
18(52.9)\end{array}$ & $\begin{array}{l}15(42.9) \\
20(57.1)\end{array}$ & $\begin{array}{l}23(63.9) \\
13(36.1)\end{array}$ & 0.1715 \\
\hline $\begin{array}{l}y \\
\text { le } \\
t\end{array}$ & $\begin{array}{l}7(20.6) \\
27(79.4)\end{array}$ & $\begin{array}{l}7(20) \\
28(80)\end{array}$ & $\begin{array}{c}4(11.1) \\
32(88.9)\end{array}$ & 0.4744 \\
\hline $\begin{array}{l}\text { id of extraction } \\
\text { 'L }\end{array}$ & $\begin{array}{l}16(47.1) \\
18(52.9)\end{array}$ & $\begin{array}{l}15(42.9) \\
20(57.1)\end{array}$ & $\begin{array}{l}24(66.7) \\
12(33.3)\end{array}$ & 0.0966 \\
\hline $\begin{array}{l}\text { tive time in minutes } \\
( \pm \text { SD) }\end{array}$ & $22.2 \pm 9.1$ & $20.2 \pm 6$ & $15.1 \pm 7.1$ & $<0.0001$ \\
\hline
\end{tabular}

SD: Standard Deviation, BMI: Body Mass Index, DB: Dormia basket, PL: Pneumatic lithotripsy.

Table 2: Score of flank pain and dysuria at different time points. 


\begin{tabular}{|c|c|c|c|c|}
\hline & $\begin{array}{c}\text { Group } 1 \\
\text { (DJ-US) } \\
n=34\end{array}$ & $\begin{array}{c}\text { Group } 2 \\
\text { (DJ-US on string) } \\
\mathrm{n}=35\end{array}$ & $\begin{array}{c}\text { Group } 3 \\
\text { (no DJ-US) } \\
n=36\end{array}$ & P-Value \\
\hline \multicolumn{5}{|c|}{$<$ pain score $\left(0-10^{\mathrm{a}}\right)($ Mean $\pm \mathrm{SD})$} \\
\hline At baseline & $8.8 \pm 1.5$ & $9.0 \pm 1.6$ & $8.8 \pm 1.5$ & $\begin{array}{l}0.5334 \\
1 \text { vs 3: } 0.7950 \\
2 \text { vs 3: } 0.2966 \\
1 \text { vs } 2: 0.3978\end{array}$ \\
\hline At 5 hours & $5.4 \pm 2.1$ & $5.8 \pm 2$ & $3.1 \pm 1.9$ & $\begin{array}{l}<0.0001 \\
1 \text { vs } 3:<0.0001 \\
2 \text { vs } 3:<0.0001 \\
1 \text { vs } 2: 0.4631\end{array}$ \\
\hline At 24 hours & $4.8 \pm 2.1$ & $4.6 \pm 2$ & $1.7 \pm 2$ & $\begin{array}{l}<0.0001 \\
1 \text { vs } 3:<0.0001 \\
2 \text { vs } 3:<0.0001 \\
1 \text { vs } 2: 0.6171\end{array}$ \\
\hline At 48 hours & $4.2 \pm 1.9$ & $3.1 \pm 1.8$ & $0.8 \pm 1.1$ & $\begin{array}{l}<0.0001 \\
1 \text { vs } 3:<0.0001 \\
2 \text { vs } 3<0.0001 \\
1 \text { vs } 20.0068\end{array}$ \\
\hline at day 7 & $4.6 \pm 2.1$ & $0.9 \pm 1.6$ & $0.6 \pm 1.7$ & $\begin{array}{l}<0.0001 \\
1 \text { vs } 3:<0.0001 \\
2 \text { vs3 } 0.3763 \\
1 \text { vs } 0.0001\end{array}$ \\
\hline At 1 month & $1.4 \pm 1.7$ & $0.14 \pm 0.49$ & $0.02 \pm 0.2$ & $\begin{array}{l}<0.0001 \\
1 \text { vs3 }<0.0001 \\
2 \text { vs3 } 0.02869 \\
1 \text { vs2 } 0.0002\end{array}$ \\
\hline \multicolumn{5}{|c|}{ Iria score $\left(0-10^{a}\right)($ Mean $\pm S D)$. } \\
\hline At 5 hours & $6.8 \pm 1.9$ & $7.3 \pm 1.8$ & $4.4 \pm 2.5$ & \begin{tabular}{|l|}
$<0.0001$ \\
1 vs3 0.0001 \\
2 vs3 $<0.0001$ \\
1 vs2 0.358
\end{tabular} \\
\hline At 24 hours & $6.3 \pm 1.9$ & $6.4 \pm 1.8$ & $2.1 \pm 1.7$ & $\begin{array}{l}<0.0001 \\
1 \text { vs3 }<0.0001 \\
2 v s 3<0.0001 \\
1 \text { vs2 } 0.8688\end{array}$ \\
\hline At 48 hours & $5.6 \pm 1.5$ & $4.7 \pm 1.6$ & $1.0 \pm 1.1$ & $\begin{array}{l}<0.0001 \\
1 v s 3<0.0001 \\
2 v s 3<0.0001 \\
1 v s 20.317 \\
\end{array}$ \\
\hline At 7 days & $5.6 \pm 1.7$ & $1.7 \pm 2$ & $0.4 \pm 1.1$ & $\begin{array}{l}<0.0001 \\
1 \mathrm{vs} 3<0.0001\end{array}$ \\
\hline
\end{tabular}




\begin{tabular}{|c|c|c|c|c|}
\hline & & & & $\begin{array}{l}2 \text { vs3 } 0.0013 \\
1 \text { vs } 2<0.0001\end{array}$ \\
\hline At 1 month & $1.6 \pm 1.7$ & $0.09 \pm 0.4$ & $0.06 \pm 0.3$ & $\begin{array}{l}<0.0001 \\
1 \text { vs3 } 0.0001 \\
2 \text { vs3 } 0.5636 \\
1 \text { vs2 }<0.0001\end{array}$ \\
\hline
\end{tabular}

No pain (0) to extreme pain (10), vs: versus, SD: standard deviation

able 3: The presence of urgency, frequency, suprapubic pain, hematuria and need for analgesia 


\begin{tabular}{|c|c|c|c|c|c|}
\hline & Time & $\begin{array}{l}\text { Group } 1 \\
\text { n (\%) }\end{array}$ & $\begin{array}{c}\text { Group } 2 \\
\text { n (\%) }\end{array}$ & $\begin{array}{c}\text { Group } 3 \\
\text { n (\%) }\end{array}$ & $P$-value \\
\hline \multirow{5}{*}{ Urgency } & $5 \mathrm{~h}$ & 32 (94.1) & $35(100)$ & 21 (58.3) & $<0.0001$ \\
\hline & $24 \mathrm{~h}$ & 30 (88.2) & $34(97.1)$ & 7 (19.4) & $<0.0001$ \\
\hline & $48 \mathrm{~h}$ & $30(88.2)$ & 31 (88.6) & $3(8.3)$ & $<0.0001$ \\
\hline & $7 d$ & $29(85.3)$ & $9(25.7)$ & $1(2.8)$ & $<0.0001$ \\
\hline & $1 \mathrm{~m}$ & $9(26.5)$ & $2(5.7)$ & $1(2.8)$ & $<0.004$ \\
\hline \multirow[t]{5}{*}{ Frequency } & $5 \mathrm{~h}$ & $32(94.1)$ & 35 (100) & $21(58.3)$ & $<0.0001$ \\
\hline & $24 \mathrm{~h}$ & 30 (88.2) & $33(94.3)$ & 7 (19.4) & $<0.0001$ \\
\hline & $48 \mathrm{~h}$ & 30 (88.2) & $30(85.7)$ & $2(5.5)$ & $<0.0001$ \\
\hline & $7 d$ & $29(85.3)$ & $8(22.9)$ & $1(2.8)$ & $<0.0001$ \\
\hline & $1 \mathrm{~m}$ & $9(26.5)$ & 0 & 0 & 0.0001 \\
\hline \multirow[t]{5}{*}{ prapubic Pain } & $5 \mathrm{~h}$ & 32 (94.1) & 33 (94.3) & 15 (41.7) & $<0.0001$ \\
\hline & $24 \mathrm{~h}$ & $29(85.3)$ & $32(91.4)$ & $4(11.1)$ & $<0.0001$ \\
\hline & $48 \mathrm{~h}$ & $26(76.5)$ & $22(62.9)$ & $2(5.5)$ & $<0.0001$ \\
\hline & $7 d$ & $27(79.4)$ & $6(17.1)$ & $1(2.8)$ & $<0.0001$ \\
\hline & $1 \mathrm{~m}$ & $5(14.7)$ & $1(2.9)$ & 0 & 0.0141 \\
\hline \multirow[t]{5}{*}{ Hematuria } & $5 \mathrm{~h}$ & $29(85.3)$ & $34(97.1)$ & $26(72.2)$ & 0.0082 \\
\hline & $24 \mathrm{~h}$ & $25(73.5)$ & $21(60)$ & 10 (27.9) & 0.0004 \\
\hline & $48 \mathrm{~h}$ & $22(64.7)$ & $12(34.3)$ & $1(2.8)$ & $<0.0001$ \\
\hline & $7 d$ & $22(64.7)$ & $3(8.6)$ & $1(2.8)$ & $<0.0001$ \\
\hline & $1 \mathrm{~m}$ & $1(2.94)$ & 0 & 0 & - \\
\hline \multirow[t]{4}{*}{ Analgesia } & $5 \mathrm{~h}$ & $31(91.2)$ & $34(97.1)$ & $21(58.3)$ & $<0.0001$ \\
\hline & $24 \mathrm{~h}$ & $28(82,4)$ & $29(82.9)$ & $8(22.2)$ & $<0.0001$ \\
\hline & $48 \mathrm{~h}$ & $24(70.6)$ & $17(48.6)$ & $3(8.3)$ & $<0.0001$ \\
\hline & $7 d$ & $26(76.5)$ & $8(22.9)$ & $1(2.8)$ & $<0.0001$ \\
\hline
\end{tabular}

h: hour; m: month; d: day

Figures 


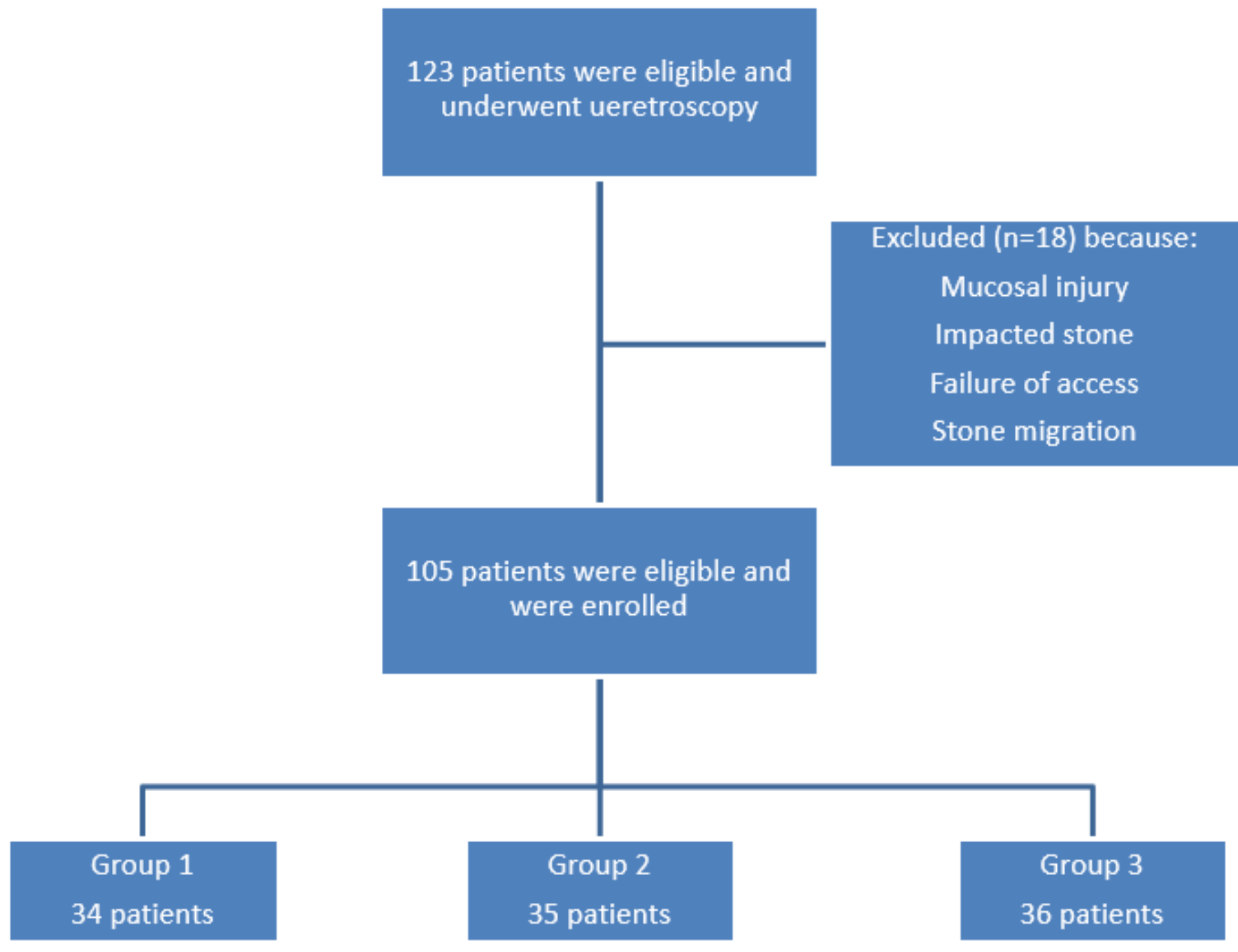

Figure 1

The flow of participants through the study

\section{Supplementary Files}

This is a list of supplementary files associated with this preprint. Click to download.

- CONSORT2010Checklist2.doc 